\title{
Minorias linguísticas, documentos biblioteconômicos e a realidade de uma biblioteca pública na Amazônia
}

\author{
Soraia Pereira Magalhães' \\ http:/ / orcid.org/ 0000-0003-2018-847X \\ ' Universidade de Salamanca, Salamanca, Espanha. \\ Doutoranda no Programa de Doutorado Formación en la Sociedad del \\ Conocimiento.
}

http:/ / dx.doi.org/ 10.1590/ 1981-5344/ 3988

Analisa o teor de 4 documentos da área biblioteconômica no tocante à atenção às minorias linguísticas e reflete sobre questões que envolvem equidade informacional a partir da análise da Biblioteca Pública de Benjamin Constant, município inserido na tríplice fronteira (Brasil, Colômbia e Peru). O multiculturalismo da região, onde estão presentes populações urbanas, povos indígenas e imigrantes de países vizinhos, põe em voga a necessidade de se discutir a atenção às minorias linguísticas e cidadania informacional. Além da revisão de literatura sobre o tema minorias linguísticas, apresenta os resultados de investigação realizada in loco, que tornou possível conhecer aspectos de infraestrutura de uma biblioteca pública amazônica (instalações, equipamentos, acervos, serviços, quadro de pessoal), bem como a impressão e a visão de 24 moradores do município (sendo 6 vinculados à área de gestão cultural; 6 indígenas da etnia Ticuna e 12 pessoas escolhidas aleatoriamente).Entre outras coisas, a investigação permitiu concluir que apesar da existência de cerca de 274 línguas indígenas apontadas no censo IBGE, 2010, pouco ou quase nada foi realizado em termos de políticas de inclusão por bibliotecas públicas, ou mesmo estudos 
bibliotecários voltados para esse grupo minoritário no Brasil.

Palavras-chave: Biblioteca Pública. Manifesto bibliotecários. Minorias Linguísticas. Indígenas. Benjamin Constant - Amazonas.

\section{Linguistic minorities, bibliotheconomic documents and the reality of a public library in Amazônia}

The paper analyzes the content of 4 documents from the Library Science area regarding attention to linguistic minorities and about issues involving equality of information to the citizens, analyzing the Public Library in Benjamin Constant, a municipality located on the triple frontier (Brazil, Colombia and Peru). The multiculturalism of the region, where urban populations, indigenous people and immigrants in neighboring countries are present, requires the attention to discuss linguistic minorities and informational citizenship. It also presents the results of on-site research, that describes the infrastructure of an Amazonian public library (facilities, equipment, collections, services, staff), and the impression and the vision of 24 residents of the municipality ( 6 being linked to the area of cultural management; 6 indigenous Ticuna and 12 randomly chosen people). The research concluded that there are no expressive advances in terms of inclusion policies within the public libraries for the 274 indigenous languages mentioned in the 2010 IBGE census in Brazil.

Keywords: Public Library. Librarians Manifesto. Linguistic minorities. Benjamin Constant, Amazonas.

Recebido em 17.02.2020 Aceito em 30.03.2020

\section{I ntrodução}


Em 2019 as Organizações das Nações Unidas(ONU) e a International Federation of Library Associations and Institutions (IFLA) comemoraram, o Ano Internacional das Línguas Indígenas(IFLA, 2019, doc. não paginado), fator que motivou o desejo de visitar documentos biblioteconômicos que atentam sobre questões das minorias linguísticas, bem como apresentar por meio de um estudo exploratório-descritivo, o contexto de uma biblioteca pública e sua relação com o tema, em uma cidade amazônica, em um estado brasileiro.

Ao celebrar o ano internacional das línguas indígenas, a ONU, ressaltava que a comemoração pretendia "alertar para a necessidade de preservar as 7 mil línguas indígenas faladas em todo o mundo. "(ONU, 2019, doc. não paginado), a ação visava gerar conscientização para a necessidade de reconhecimento e preservação; foi no mesmo sentido, que a IFLA encampou a ideia de motivaras bibliotecas públicas a apresentarem o que estavam realizando em prol das minorias linguísticas.

No Brasil, o contexto populacional indígena é expressivo, pois de acordo com o Censo 2010, haviam 897 mil indígenas, distribuídos entre 305 etnias, sendo falantes de 274 línguas.(IBGE, 2010).Outros dados apontavam ainda que do montante de 10 municípios brasileiros com maior quantitativo populacional indígena, 6 estavam localizados no estado do Amazonas, sendo eles: São Gabriel da Cachoeira, São Paulo de Olivença, Tabatinga, Santa Isabel do Rio Negro, Barcelos e Benjamin Constant. (IBGE, 2012, p. 16).

Visando refletir sobre atenção as minorias linguísticas no âmbito das bibliotecas públicas no Brasil, esse artigo tomou por base as referências contidas em quatro documentos da literatura Biblioteconômica, dos quais - Manifesto da IFLA/UNESCO para Bibliotecas Públicas (IFLA/UNESCO, 1994); Diretrizes da IFLA sobre os Serviços da Biblioteca Pública (KOONTZ; GUBBIN, 2013); o pouco conhecido ou referendado Manifesto das Bibliotecas da Amazônia (MANIFESTO DAS BIBLIOTECAS DA AMAZÔNIA, 2005), além da publicação brasileira Biblioteca Pública: Princípios e Diretrizes(FUNDAÇÃO BIBLIOTECA NACIONAL, 2010). Para a composição das análises foram também dedicadas leituras em documentos como a Declaração Universal dos Direitos Humanos, Declaração Universal dos Direitos Linguísticos, bem como na Constituição Federal Brasileira de 1988.

Ao tocar o tema minorias linguísticas é impossível não refletir sobre a condição da biblioteca indígena no Brasil; contudo, em levantamento bibliográfico realizado foi possível perceber escassez de estudos desenvolvidos nesse campo por profissionais bibliotecários, mas há de se destacar, porém, os trabalhos desenvolvidos pela bibliotecária Aline Franca, que reflete sobre aspectos da representação bibliográfica do conhecimento indígena registrado; bem como as produções de José 
Ribamar Bessa Freire, único autor brasileiro referenciado na obra “Bibliotecas indígenas en América Latina: Revisión bibliográfica y estado actual de la cuestión", de Edgardo Civallero, que faz considerações sobre bibliotecas indígenas em países como: Argentina, Brasil, Bolívia, Colômbia, Costa Rica e outros. (CIVALLERO, 2008).

A análise, além de destacar os aspectos teóricos contidos nos documentos biblioteconômicos, apresenta informações voltadas para a realidade amazônica, por meio de investigação realizada no município de Benjamin Constant e sua biblioteca pública. A justificativa para a escolha do município firmou-se no fato de estar localizado nas entranhas da floresta, dispondo na sua área urbana da presença marcante de indígenas, além de expressivo convívio com estrangeiros, em vista de sua posição nas cercanias entre Colômbia e Peru.

Partiu-se da hipótese de que a Biblioteca Pública Municipal Francisco Soares de Assis, instalada no município de Benjamin Constant, poderia representar alguns pontos de integração entre os grupos minoritários, contudo, apesar de possuir edifício próprio, inclusive com auditório para reuniões, além de possuir localização na região central e salão de leitura, dispunha de acervos de livros e equipamentos em condições precárias, além de realizar poucos serviços. A Biblioteca não contava com profissionais da área biblioteconômica, bem como não possuía material bibliográfico que atendesse às demandas multilinguísticas presentes na região. O município, porém, dispõe em sua área urbana do Museu Maguta, estrutura cultural criada pelo povo indígena Ticuna, que se destaca mais que a biblioteca pública municipal. O Maguta tem sido objeto de interesse de produções acadêmicas que refletem sobre o espaço museológico e sua formação vinculada à ativa participação do povo Ticuna.

Do ponto de vista metodológico, a pesquisa se insere como Qualiquantitativa de cunho exploratório e descritiva. O trabalho contribui para análises desenvolvidas sobre cidades do Amazonas, seguindo parâmetros estabelecidos pelo Núcleo de Estudos e Pesquisas das Cidades na Amazônia Brasileira (NEPECAB), que buscam compreender o modo de viver nas cidades amazônicas a partir do entendimento sobre a rede urbana no Amazonas. Para o NEPECAB, o município de Benjamin Constant pode ser definido como uma Cidade Pequena de Responsabilidade Territorial. Especificamente sobre cidades dessa natureza, Schore Oliveira (2011, p. 20) apontam que "as cidades de fronteira também devem ser consideradas nesta tipologia de forma diferenciada, pois exercem um papel específico e constituem redes de relações próprias de abrangência internacional. "

Para o desenvolvimento da pesquisa de campo foi utilizado como base, o formulário criado em 2011 pelo Sistema Nacional de Bibliotecas Públicas, da Fundação Biblioteca Nacional do Brasil, (com alguns ajustes) 
como forma de descrever os espaços da biblioteca e o perfil da instituição. Para conhecer a visão da população sobre o papel da biblioteca pública, foram realizadas entrevistas com amostra populacional composta por 24 pessoas, sendo 6 vinculados à área de gestão do município; 6 indígenas da etnia Ticuna e 12 pessoas escolhidas aleatoriamente visando saber 0 nível de interação com a biblioteca pública. As atividades de campo desenvolvidas sem Benjamin Constant aconteceram nos anos de 2012 e 2017. Especificamente para essa análise optou-se por apresentar os dados obtidos em 2017.

Os quatro documentos que serão apresentados elevam as potencialidades do equipamento cultural biblioteca pública, salientando sua abrangência na relação com os princípios de justiça social e se adequam ao direito à cultura, previsto na Constituição Federal Brasileira de 1988, onde o Artigo 215aponta que “O Estado garantirá a todos o pleno exercício dos direitos culturais e acesso às fontes da cultura nacional, e apoiará e incentivará a valorização e a difusão das manifestações culturais. "(BRASIL, 1988, p. 126). Na mesma página do documento, assegura que "O Estado protegerá as manifestações das culturas populares, indígenas e afro-brasileiras, e das de outros grupos participantes do processo civilizatório nacional."(BRASIL, 1988, p. 126).

Contudo, até que ponto os cidadãos brasileiros estão cientes de informações dessa natureza? Num país com grandes desigualdades sociais, as bibliotecas públicas poderiam servir como pontos de equilíbrio para assegurar princípios básicos de democracia, onde informações sobre direitos deveriam ser expressivos, contudo a realidade é que as bibliotecas públicas ocupam pouco interesse nas agendas governamentais, fator que impacta principalmente os grupos minoritários.

\section{Minorias: manifestos e diretrizes}

As Declarações e Manifestos podem ser vistos como documentos de cunho democrático que atuam de forma a servir como pontos de esclarecimentos, recomendações e intenções. Ao longo da história, vários desses documentos têm influenciado estruturas mundiais a pensar de forma cidadã, sendo um dos mais importantes, a Declaração Universal dos Direitos Humanos, adotada pela Organização das Nações Unidas em 1948 (ONU, 1948, doc. não paginado), que por meio de 30 artigos salienta valores fundamentais para a vida entre os povos. $O$ artigo 27 da Declaração Universal dos Direitos Humanos se adequa especificamente sobre o tema das bibliotecas públicas ao apontar que: "Todo ser humano tem o direito de participar livremente da vida cultural da comunidade, de fruir as artes e de participar do progresso científico e de seus benefícios."(ONU, 1948, doc. não paginado). 
Tendo completado 70 anos em 10 de dezembro de 2018, a Declaração Universal dos Direitos Humanos esboça de forma muito clara aspectos que envolvem justiça e solidariedade, além de respeito à vida, à paz e à liberdade.

Outro documento relevante para essa análise consiste na Declaração Universal dos Direitos Linguísticos, publicada pela UNESCO em 1996, elaborada a partir de uma série de estudos, debates e recomendações que tratam sobre reconhecimento e direitos voltados para as diversidades linguísticas. Do ponto de vista conceitual, o documento orienta que uma comunidade linguística pode ser vista como:

[...] toda a sociedade humana que, radicada historicamente num determinado espaço territorial, reconhecido ou não, se identifica como povo e desenvolveu uma língua comum como meio de comunicação natural e de coesão cultural entre os seus membros. A denominação língua própria de um território refere-se ao idioma da comunidade historicamente estabelecida neste espaço. (PEN CLUBE PORTUGUÊS, 1996, doc. não paginado).

A Declaração Universal dos Direitos Linguísticos deveria exercer forte influência sobre o contexto brasileiro, tendo em vista o país estar inserido numa conjuntura plurilinguística, fator desconhecido por muitos, sendo consideradas apenas línguas oficiais o Português e a Língua Brasileira de Sinais. Informações dessa natureza, porém, deveriam impactar o contexto das bibliotecas no tocante à formação e ao desenvolvimento de coleções, além de serviços no atendimento às minorias.

Vejamos, porém, o que dizem os Manifestos e diretrizes criados, especificamente para as bibliotecas públicas, no tocante às minorias linguísticas.

No Manifesto da IFLA/UNESCO para bibliotecas públicas, (IFLA/UNESCO, 1994), a inserção do pensamento voltado para atenção às minorias linguísticas está contida logo na introdução:

Os serviços da biblioteca pública devem ser oferecidos com base na igualdade de acesso para todos e serviços e materiais específicos devem ser postos à disposição dos utilizadores que, por qualquer razão, não possam usar os serviços e os materiais correntes, como, por exemplo, minorias linguísticas, pessoas com deficiências, hospitalizadas ou reclusas. (IFLA/UNESCO, 1994).

Mundialmente aceito, o Manifesto da IFLA/UNESCO para bibliotecas públicas que em 2019completou 25 anos, proclama 12 missões essenciais que se convergem em prol de uma sociedade mais justa, aliada ao acesso 
à informação, à alfabetização, à educação e à cultura. Muito da essência contida nesse documento foi refletida e exemplificada na publicação Diretrizes da IFLA sobre os serviços da biblioteca pública, considerado instrumento de apoio ao trabalho bibliotecário, pois não só amplia a visão em torno do que apresenta o Manifesto de 1994, como aponta outras informações sobre bibliotecas públicas atuantes e comprometidas. Em Diretrizes da IFLA, a biblioteca pública é definida como:

[...]uma organização criada, mantida e financiada pela comunidade, quer através da administração local, regional ou central, quer através de outra forma de organização comunitária. Disponibiliza acesso ao conhecimento, à informação, à aprendizagem ao longo da vida e a obras criativas, através de um leque alargado de recursos e serviços, estando disponível a todos os membros da comunidade independentemente de raça, nacionalidade, idade, gênero, religião, língua, deficiência, condição econômica e laboral e nível de escolaridade. (KOONTZ; GUBBIN, 2013, p. 13).

A definição, ao atribuir aspectos que implicam investimentos e recursos, instiga o pensamento de que uma biblioteca, para existir de forma a promover acessibilidade para todos, deve ser gerida e mantida por alguma entidade. Sem recursos, sem uma política permanente de investimentos, bibliotecas até nascem, mas tornam-se frágeis e, por conseguinte, podem ser extintas ou seguir apenas existindo, sem executar sua efetiva função.

No Brasil, a publicação Biblioteca Pública: Princípios e Diretrizes, edição de 2010, elaborada sob a responsabilidade da Biblioteca Nacional e a Coordenação do Sistema Nacional de Bibliotecas Públicas define que:

A biblioteca pública é um elo entre a necessidade de informação de um membro da comunidade e o recurso informacional que nela se encontra organizado e à sua disposição. Além disso, uma biblioteca pública deve constituir-se em um ambiente realmente público, de convivência agradável, onde as pessoas possam se encontrar para conversar, trocar ideias, discutir problemas, auto instruir-se e participar de atividades culturais e de lazer. (FUNDAÇÃO BIBLIOTECA NACIONAL, 2010, p. 18).

A publicação brasileira, porém, sobre o tema focal dessa análise, apenas reproduz o que já havia sido escrito, não apresentando informações sobre minorias linguísticas além dos dados já contidos no Manifesto da IFLA/UNESCO para bibliotecas públicas. Apesar de estimular 
a realização de estudos de comunidade, não propõe nenhum mecanismo de atuação voltado para atenção a esse público, questão que vem sendo negligenciada e pouco debatida pela área biblioteconômica brasileira ao longo do tempo.

Por fim, o desconhecido e pouco referendado (MANIFESTO DAS BIBLIOTECAS DA AMAZÔNIA, 2005), que foi elaborado durante o I Encontro de Bibliotecas Públicas da Amazônia (realizado no período de 5 a 9 de maio de 2004, em Belém do Pará, em evento organizado pelo Conselho Regional de Biblioteconomia (CRB 2) e Associação Paraense de Bibliotecários), ao proclamar a função social da biblioteca pública, o documento atribui caráter indispensável a sustentabilidade, ao defini-la como:

Instituição imprescindível para o desenvolvimento integral e sustentável da sociedade, contribuindo decisivamente para a diminuição das desigualdades sociais, o combate à pobreza, a promoção da paz e da solidariedade humana. (MANIFESTO DAS BIBLIOTECAS DA AMAZÔNIA, 2005, p. 7).

No tocante às questões das minorias, aponta como metas de construção da cidadania, o atendimento voltado para "[...] as crianças, os jovens, os idosos, os desempregados, os analfabetos e iletrados e os habitantes das zonas rurais, dos aldeamentos indígenas e quilombolas." (MANIFESTO DAS BIBLIOTECAS DA AMAZÔNIA, 2005, p. 11).

O Manifesto das Bibliotecas da Amazônia, além de apresentar considerações fundamentais para o desenvolvimento de ações nas bibliotecas, salienta no artigo 24 que a biblioteca pública tem

[...] papel decisivo na contribuição à formação da consciência ecológica dos cidadãos, capacitando-os a atuar de maneira responsável e consequente nas lutas pela preservação da vida no planeta, de maneira geral, e na Amazônia, em particular. (MANIFESTO DAS BIBLIOTECAS DA AMAZÔNIA, 2005, p. 12).

No momento em que o mundo assiste os efeitos provocados pelas mudanças climáticas, pensar a biblioteca pública como um dos braços para a estratégia de educação ambiental pode ser um investimento que trará benefícios a longo prazo, medida absolutamente necessária para o Brasil, haja vista que a Amazônia absorve entre outras coisas a maior biodiversidade do planeta, bem como a maior bacia hidrográfica do mundo.

Definida a biblioteca pública nos quatro documentos, buscou-se extrair dados significativos sobre o que orientam quanto ao fazerno atendimento às minorias linguísticas, sendo constatado que apenas As 
Diretrizes da IFLA sobre os serviços da biblioteca pública apresentavam considerações mais aprofundadas ao referendar o atendimento voltado para três aspectos fundamentais: recursos humanos, acervos e serviços, além de atenção redobrada para o serviço de referência que deve ser realizado com atuação capacitada, que vá além da cortesia, com informações que atendam às necessidades e promovam acolhimento. No quadro 1, constam os elementos propostos a considerar quanto ao atendimento às minorias:

Quadro 1. O que uma biblioteca deve dispor para atender as minorias

\begin{tabular}{|c|l|}
\hline O que considerar & \multicolumn{1}{c|}{ Atenção } \\
\hline Recursos Humanos & $\begin{array}{l}\text { A imagem transmitida por todas as bibliotecas deve ser isenta e objetiva. O } \\
\text { pessoal deve ser sempre cortês, afável, respeitoso e disposto a ajudar, deve } \\
\text { existir um programa de formação regular para estes, sobre atendimento ao } \\
\text { utente todo o pessoal deve receber formação básica sobre como lidar com } \\
\text { pessoas portadoras de deficiência e pertencente a minorias étnicas }\end{array}$ \\
\hline Serviços e materiais & $\begin{array}{l}\text { Serviços e materiais específicos devem ser postos à disposição dos } \\
\text { utilizadores que, por qualquer razão, não possam usar os serviços e os } \\
\text { materiais correntes, como, por exemplo, minorias linguísticas, pessoas } \\
\text { deficientes, hospitalizadas ou reclusas. Todos os grupos etários devem } \\
\text { encontrar documentos adequados às suas necessidades. }\end{array}$ \\
\hline Coleções especiais & $\begin{array}{l}\text { Proporção de grupos específicos, como por exemplo crianças, reformados, } \\
\text { jovens, populações indígenas, minorias étnicas ou desempregados devem } \\
\text { refletir as necessidades destes grupos nas suas coleções e serviços. }\end{array}$ \\
\hline
\end{tabular}

Fonte: Koontz e Gubbin (2013), páginas 46, 47 e 64.

No contexto da chamada Sociedade da Informação, além dos três aspectos apontados, o acesso a computadores com acesso à Internet deveria ser elemento indispensável, inclusive por oferecer traduções em linha, além de contribuir de forma geral para a inserção de pessoas que vivem em condição de exclusão digital.

As Diretrizes da IFLA para Bibliotecas apresentam alguns exemplos de países que têm investido em bibliotecas públicas e desenvolvem ações relevantes voltadas para o atendimento às minorias linguísticas. 
Quadro 2. Exemplos de atuação voltada para as minorias linguísticas em alguns países

\begin{tabular}{|c|c|c|}
\hline PAÍSES & QUE FAZ & Atividades \\
\hline Dinamarca & $\begin{array}{l}\text { O Laboratório para a Integração de Minorias Étnicas da } \\
\text { Dinamarca centra-se na oferta de serviços bibliotecários a estas } \\
\text { populações, com base em teorias de «capacitação e criação de } \\
\text { novos públicos » de forma a criar novos serviços de biblioteca e a } \\
\text { melhorar os existentes. }\end{array}$ & Capacitação \\
\hline Noruega & $\begin{array}{l}\text { A Biblioteca Pública de Oslo, na Noruega, mantém um serviço de } \\
\text { Internet customizado em } 14 \text { línguas, para minorias linguísticas. } \\
\text { Este contém informação sobre bibliotecas, cultura, sociedade } \\
\text { norueguesa, e como aprender a língua norueguesa e identifica } \\
\text { organizações dirigidas às minorias. }\end{array}$ & $\begin{array}{c}\text { Tecnologia/ } \\
\text { Internet }\end{array}$ \\
\hline Venezuela & $\begin{array}{l}\text { Os bibliotecários de Amazonas, na Venezuela, foram formados } \\
\text { para agir como intermediários entre diferentes culturas, uma vez } \\
\text { que muitas pessoas que habitam as comunidades rurais apenas } \\
\text { falam e compreendem a sua língua nativa. }\end{array}$ & $\begin{array}{c}\text { Relações } \\
\text { Interpessoais }\end{array}$ \\
\hline $\begin{array}{c}\text { Nova Jérsia, } \\
\text { EUA }\end{array}$ & $\begin{array}{l}\text { A Biblioteca Pública de Newark, Nova Jérsia, EUA, criou o } \\
\text { Centro de Informação Charles Cummings de Nova Jérsia dedicado } \\
\text { à história local e estadual, em parceria com a Comissão Histórica } \\
\text { de Nova Jérsia. }\end{array}$ & Memória \\
\hline Croácia & $\begin{array}{l}\text { As bibliotecas centrais da República da Croácia prestam serviços } \\
\text { bibliotecários a todas as minorias étnicas, incluindo livros na sua } \\
\text { língua mãe, exposições, eventos culturais e literários e empréstimo } \\
\text { interbibliotecas para suprir necessidades das várias comunidades } \\
\text { locais. }\end{array}$ & $\begin{array}{c}\text { Atividades } \\
\text { culturais e } \\
\text { acervos }\end{array}$ \\
\hline Austrália & $\begin{array}{l}\text { As bibliotecas do município de Gold Coast, na Austrália, celebram } \\
\text { «As culturas da Costa» com programas mensais de interesse } \\
\text { multicultural, organizados e realizados por grupos diversos, a fim } \\
\text { de sensibilizar a comunidade para a diversidade cultural. }\end{array}$ & $\begin{array}{l}\text { Atividades } \\
\text { Culturais }\end{array}$ \\
\hline
\end{tabular}

Fonte: Koontz e Gubbin, 2013, p. 43.

É possível complementar esse quadro de exemplos com experiência pessoal observada in loco junto ao Sistema de Bibliotecas Públicas de Estocolmo, na Suécia, onde foi possível constatar que quase todas as 44 bibliotecas públicas da capital contavam com acervos não restritos à língua sueca. Além disso, a cidade possuía a Internationella Biblioteket, que disponibilizava materiais bibliográficos distribuídos em mais de 100 línguas, com acervos formados por cerca de 200 mil livros, além de equipe com formação multilinguística. 
Apesar do Brasil se espelhar teoricamente nos parâmetros contidos no Manifesto da IFLA para Biblioteca Públicas, ainda não avançamos de forma a tornar a biblioteca pública brasileira presente, atuante, democrática e inclusiva, condição que tem trazido danos para o país. Suaiden(2018, p. 1143), ao refletir sobre competências para as bibliotecas públicas no século XXI, apontou que:

En una sociedad de la información / conocimiento donde la verdad es a menudo cuestionada por los dueños del poder, por la hegemonía existente, por los intereses contrariados, por las ideologías y las políticas implementadas, la biblioteca debería ser un centro de resistencia en busca de la verdad. (SUAIDEN, 2018, p. 1143).

A afirmação se adequa perfeitamente à reflexão sobre o contexto brasileiro diante das eleições de 2018, quando a manipulação de informações promovida por fake news gerou um quadro de desinformação, mobilizações insensatas, discursos de ódio e perdas substanciais para a democracia do país. Talvez se tivéssemos bibliotecas públicas inclusivas e atuantes teríamos uma sociedade melhor formada, mais sensível às injustiças sociais e mais consciente diante de tomadas de decisões, mas, para isso, é preciso compreensão de que boas bibliotecas públicas vão além de livros, computadores e acesso à internet. Bibliotecas públicas precisam do compromisso de pessoas com conhecimentos e disponibilidades para desempenhar ações em prol da integridade humana, da informação, da cultura e da democracia.

Os quatro documentos biblioteconômicos referendados não expressam mais do que foi exposto sobre minorias linguísticas, mesmo por que sinalizam visões generalizadas no campo das bibliotecas públicas. O tema é focal e diante da conjuntura brasileira necessita ser detidamente estudado.

Vejamos a condição da Biblioteca Pública do município de Benjamin Constant, no estado do Amazonas, onde proponho o exercício de reflexão quanto a conjuntura do que será apresentado, com as definições apontadas nos documentos sobre o que são efetivamente bibliotecas públicas.

\section{Biblioteca pública: o caso de Benjamin Constant}

Benjamin Constant, possui área territorial de $8793,429 \mathrm{~km}^{2}$ e população estimada em42.984 habitantes (IBGE, 2019), está localizado no Alto Solimões, distante em linha reta cerca de $1.118 \mathrm{~km}$ da cidade de Manaus. Os meios de acesso ao município são fluviais, mas é possível chegar por via aérea de Manaus até Tabatinga, cidade amazonense que 
faz fronteira com Letícia, na Colômbia. O percurso final ao município necessariamente ocorre por barco.

No Censo de 2010, em termos nacionais, o município ocupava a sexta posição pelo quantitativo populacional indígena em área urbana (9.833) e o quarto mais populoso em área rural (8.704), com grande percentual de indígenas da etnia Ticuna. Almeida (2005, p. 47), que analisou economia e sociedade Ticuna, no tocante ao quantitativo populacional, apontou que "Os Ticuna são, talvez, o mais numeroso povo indígena em território brasileiro, com uma população estimada em cerca de 25.000 índios apenas desse lado da fronteira, habitando, ainda que em menor número, também o Peru e a Colômbia". O município absorve também quantitativo populacional de colombianos e peruanos que buscam nas terras brasileiras, entre outras coisas, oportunidades de acolhimento, moradia e trabalho.

Benjamin Constant é conhecido como a "Capital Cultural do Alto Solimões" não pelas ações desenvolvidas por sua biblioteca pública, mas talvez pelas presenças de um pólo da Universidade Federal do Amazonas (UFAM), ou as ações do Museu Maguta, administrado pelo povo indígena Ticuna ou por suas festas, das quais o festival folclórico que envolve as disputas entre os bois bumbás Mangagá e Corajoso, seguindo os moldes do Festival Folclórico de Parintins.

A história de Benjamin Constant tem relação com o processo de ocupação e formalização de posse colonial portuguesa na região. De acordo com dados do IBGE "Por volta de 1750 já existia nas proximidades da foz do Javari, no Solimões, a aldeia do Javari, onde viviam os índios Ticunas, fundadas pelos jesuítas." (IBGE, 2019).

Apesar de ocuparem as áreas desde os primeiros tempos, os Ticunas tiveram que travar várias lutas para terem suas terras demarcadas, e, foi em meio a esse processo que surgiu o Museu Maguta em 1988. Benjamin Constant é um dos poucos municípios do Amazonas que possui uma biblioteca pública e um museu. O Maguta atende, porém, uma peculiaridade: foi criado pelos índios Ticuna e reúne materiais e registros informacionais que visam à preservação da memória e cultura desse povo. Sobre a formação do espaço, de acordo com Freire (1999, p. 1):

[...] os índios participaram ativamente na organização do acervo, colaborando na definição dos objetos, no levantamento dos dados sobre cada peça, na seleção daquelas destinadas à exposição e no desenho das ilustrações para sua contextualização. (FREIRE, 1999, p. 1).

O Museu Maguta ocupa uma casa de alvenaria que dispõe de cinco ambientes, com uma pequena sala reservada para a biblioteca 
especializada. A 200 metros do Maguta está localizada a Biblioteca Pública Municipal Francisco Soares de Assis, que foi criada sema participação da sociedade.

Figura 1. Edifício da Biblioteca Pública de Benjamin Constant

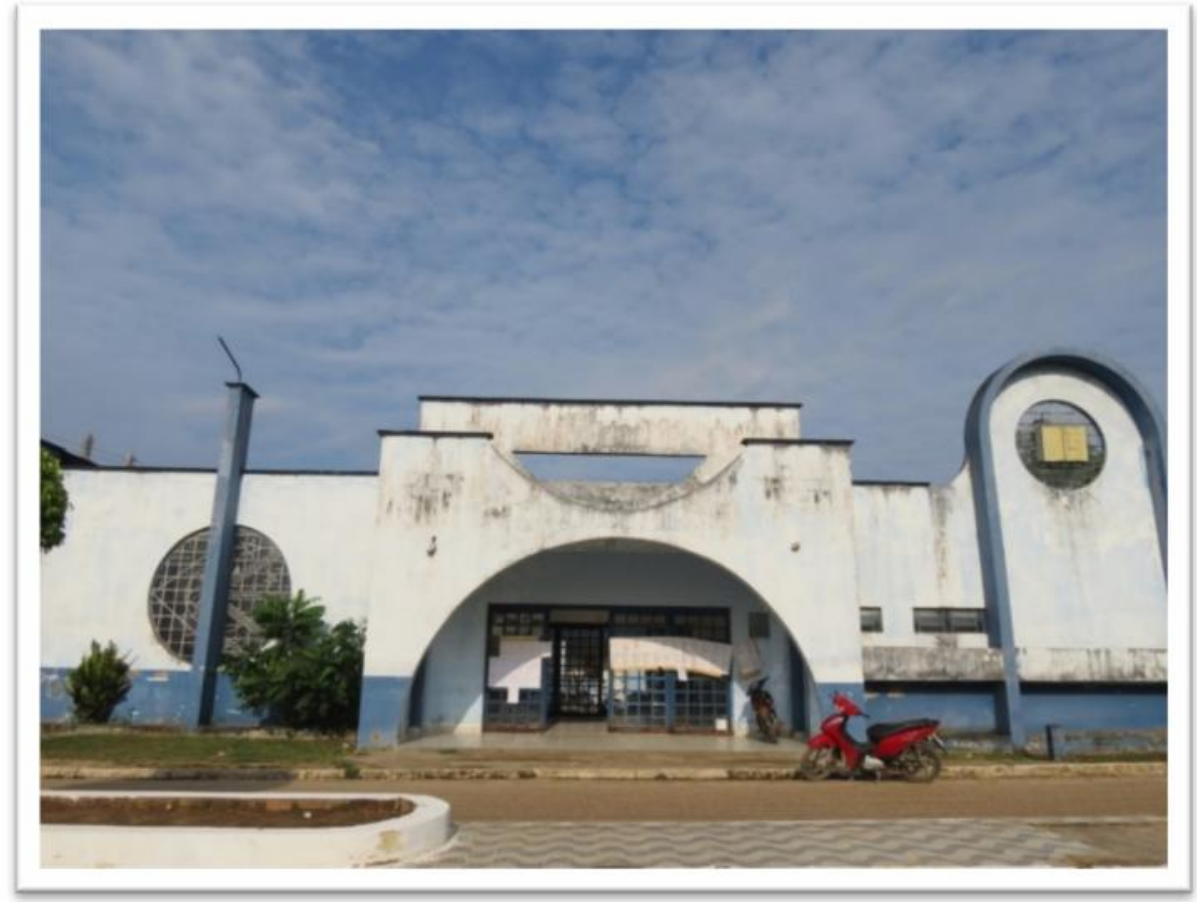

Fonte: Peter Janzon (2017)

Benjamin Constant fez parte dos primeiros municípios amazonenses a viabilizar a criação de uma biblioteca pública, inclusive formalizada pela Lei n. 452/79, aprovada na Câmara Municipal de Benjamin Constant em 19 de janeiro de 1979 (AMAZONAS, 1979). A Biblioteca conta com edifício próprio, construído por convênio estabelecido entre a Secretaria de Planejamento e Coordenação Geral do município, com recursos federais do Fundo Nacional de Desenvolvimento Urbano (BRASIL, 1975).

Baseada no modelo de formulário criado pelo SNBP para o cadastro nacional de bibliotecas públicas em 2011, a investigação visava abarcar informações sobre infraestrutura, gestão, público alvo, acervo, serviços.Para melhor adequação do objeto dessa investigação, foram adicionadas perguntas sobre a existência de acervos e serviços voltados para as minorias linguísticas. O quadro 3 apresenta o resultado dos dados coletados a partir de informações disponibilizadas por 3 funcionários. 


\section{Quadro 3. Condição Biblioteca Municipal de Benjamin Constant}

\begin{tabular}{|c|c|}
\hline Perguntas & Observação \\
\hline O município possui biblioteca pública? & $\begin{array}{l}\text { Biblioteca Pública Municipal Francisco } \\
\text { Soares de Assis }\end{array}$ \\
\hline $\begin{array}{l}\text { A BP possui documento de Criação e prédio } \\
\text { próprio? }\end{array}$ & $\begin{array}{l}\text { Possui prédio próprio e foi criada Lei n. } \\
\text { 452/79, aprovada na Câmara Municipal de } \\
\text { Benjamin Constant em } 19 \text { janeiro de } 1979 .\end{array}$ \\
\hline Situação de Funcionamento & Ativa \\
\hline A biblioteca é aberta ao público em geral? & Sim \\
\hline Faixa etária predominante dos usuários & 12 a 20 anos \\
\hline Trabalha com grupos específicos & Não \\
\hline Frequência média mensal dos usuários & 30 pessoas \\
\hline Total aproximado de itens do acervo & Mais de 1000 itens \\
\hline Forma de aquisição do acervo & Doação \\
\hline Tipos de suportes que compõem o acervo & Livros, revistas, CDs, DVDs \\
\hline $\begin{array}{l}\text { Possui material que atenda as minorias } \\
\text { linguísticas? }\end{array}$ & Não \\
\hline Qual o sistema de classificação utilizado & Nenhum \\
\hline Possui catálogo bibliográfico? & Não - Foi iniciado, mas o trabalho se perdeu \\
\hline O acesso às estantes é aberto ou restrito? & Acesso aberto \\
\hline Quais os serviços oferecidos? & $\begin{array}{l}\text { Consulta local e empréstimo domiciliar, } \\
\text { orientação a pesquisas escolares e acadêmicas }\end{array}$ \\
\hline $\begin{array}{l}\text { Desenvolve serviços para as minorias } \\
\text { linguísticas ou deficientes físicos? }\end{array}$ & Não \\
\hline $\begin{array}{l}\text { A biblioteca possui espaços de } \\
\text { Conveniências? (restaurante, lanchonete, } \\
\text { livraria, estacionamento) }\end{array}$ & Não \\
\hline $\begin{array}{l}\text { A biblioteca possui serviço de extensão } \\
\text { (Caixa-estante,Ônibus biblioteca, } \\
\text { Atividades de leitura fora da biblioteca) }\end{array}$ & Não \\
\hline $\begin{array}{l}\text { A biblioteca desenvolve eventos culturais } \\
\text { como (Mediação de leitura; Grupos de } \\
\text { leitura, Palestras, cursos, etc) }\end{array}$ & $\begin{array}{c}\text { Realizava atividades no auditório (palestras, } \\
\text { cursos) }\end{array}$ \\
\hline Área construída aproximada da biblioteca & Não souberam responder \\
\hline $\begin{array}{l}\text { Acessibilidade física (Banheiros } \\
\text { adaptados,Rampa de acesso, outros) }\end{array}$ & Não \\
\hline Capacidade total da biblioteca? & No salão de leitura 30/ auditório 100 \\
\hline Espaços (Cabines para trabalho em grupo, & Auditório, área para exposições \\
\hline
\end{tabular}




\begin{tabular}{|l|c|}
\hline $\begin{array}{l}\text { Salas para acesso à internet, Espaços } \\
\text { infantis, Auditórios, outros) }\end{array}$ \\
\hline $\begin{array}{l}\text { Quanto aos equipamentos disponíveis (Ar } \\
\text { condicionado, Computadores com ou sem } \\
\text { acesso internet, Rede Wi-Fi, etc) }\end{array}$ & Não possuía os equipamentos listados \\
\hline A Biblioteca possui Regulamento? & Sim \\
\hline Quem administra a biblioteca? & Prefeitura Municipal \\
\hline Quantidade de funcionários & Não \\
\hline Contava com bibliotecários? & Haviam recebido revistas enviadas pelo \\
\hline $\begin{array}{l}\text { Recebeu apoio de Programas } \\
\text { Governamentais (Livro Aberto, outros) }\end{array}$ & Ninistério da Cultura \\
\hline A biblioteca participa ou participou de & \\
Rede de biblioteca? & \\
\hline $\begin{array}{l}\text { Recebeu apoio do Sistema Estadual de } \\
\text { Bibliotecas Públicas - SEBP/AM? }\end{array}$ & Não \\
\hline
\end{tabular}

Fonte: A autora (2019)

Conforme destacado por um dos funcionários, a Biblioteca Pública de Benjamin Constant contou nos anos 90 com a atuação de um bibliotecário, mas depois de seu desligamento, o processo de tratamento técnico do acervo foi abandonado.

Em 2017 a Biblioteca possuía um salão de leitura que acomodava 11 estantes dupla faces, confeccionadas em aço. No acervo, era visível perceber o acúmulo de livros de um mesmo título em número superior ao necessário, além de muitos livros didáticos, revistas e enciclopédias. A Biblioteca chegou a dispor de uma sala reservada para o atendimento do público infantil, contudo havia sido desativada e adaptada para receber o setor administrativo da Secretaria de Cultura Municipal. 
Figura 2. Crianças na Biblioteca Pública de Benjamin Constant

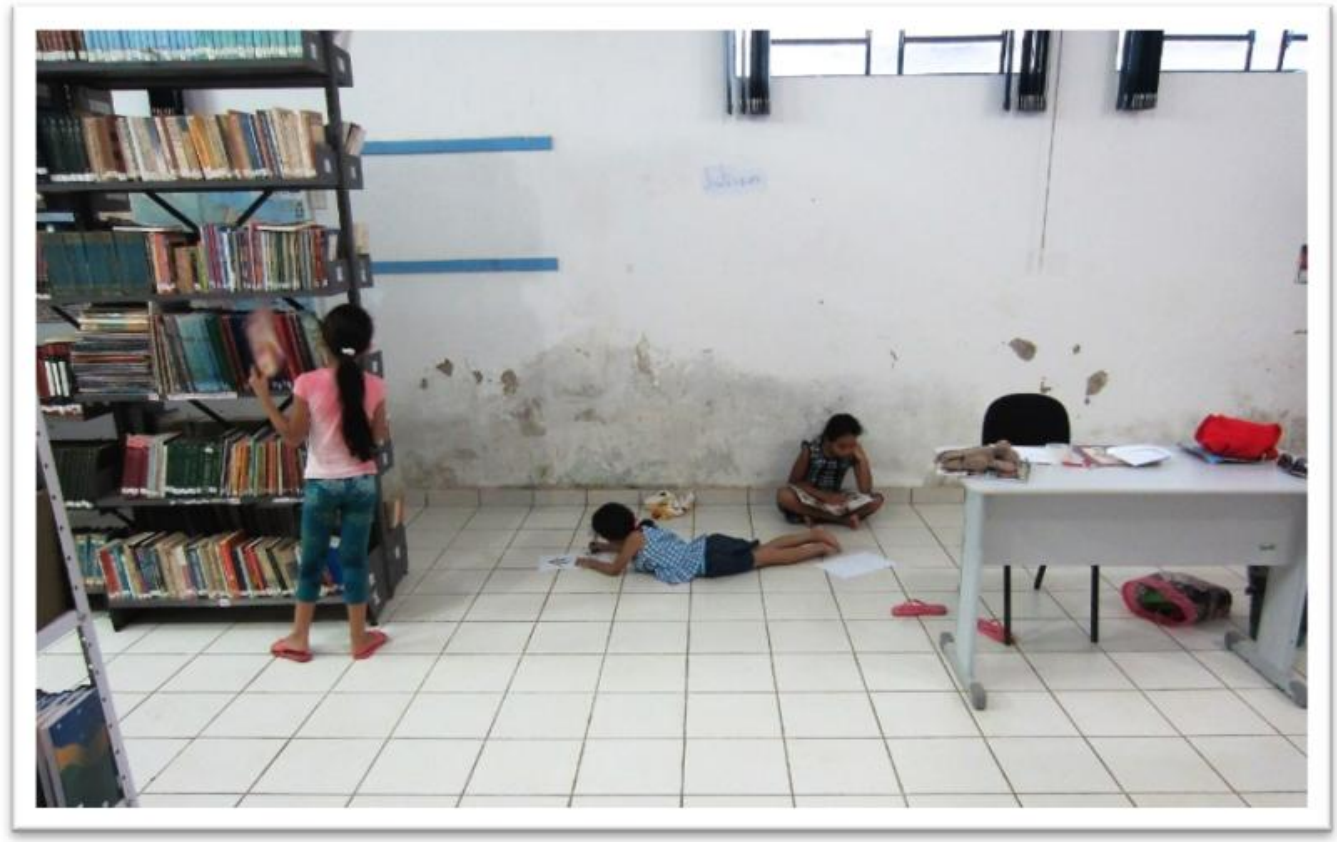

Fonte: Peter Janzon (2017)

A investigação em Benjamin Constant ocorreu em fevereiro de 2017, durante três dias consecutivos em horários distintos; no último dia foi possível encontrar, por volta das 16 horas, três meninas com idades entre 10 e 12 anos desenhando e fazendo leituras. No espaço que ocupavam, junto às estantes era possível perceber na parede condições de mofo e umidade. Nas estantes não haviam livros voltados para suas faixas etárias e ao final, estantes, cadeiras e mesas não ofereciam comodidade.

O horário de funcionamento da Biblioteca era de 08 às 18 horas de segunda a sexta-feira. Sem computadores com acesso à Internet, sem dispor de acervos para atender as minorias linguísticas, sem atividades culturais voltadas para crianças, adultos, indígenas, idosos, mulheres, público LGTB e imigrantes, a biblioteca pública recebia poucos usuários.

\subsection{I mpressões do corpo técnico}

A investigação possibilitou entrevistar o Secretário de Cultura do município, 2 funcionários da biblioteca e 1funcionário da Secretaria de Cultura, além de Francisca Pinto, que atuou nos primeiros anos como funcionária da Biblioteca, e seguiu tempos depois a carreira na área biblioteconômica. Para as análises, além de questionamentos voltados para os aspectos de infraestrutura, foram realizadas perguntas que visavam saber se os entrevistados vinculados à administração pública possuíam conhecimentos sobre o teor do Artigo 215 da Constituição Federal Brasileira de 1988, que dispõe sobre direitos culturais, bem como sobre o Manifesto da IFLA/UNESCO para bibliotecas públicas. Todos 
afirmaram dispor de informação sobre o artigo 215 da Constituição, enquanto que em relação ao Manifesto da IFLA para bibliotecas públicas, apenas Francisca Pinto apontou dispor desse conhecimento. Para a investigação foi relevante a entrevista realizada com o antropólogo Anderson Rocha de Almeida, que havia assumido a Secretaria de Cultura do município em janeiro de 2017. Indagado sobre sua visão referente à biblioteca pública e o atendimento às minorias, especialmente aos povos indígenas, comentou:

\begin{abstract}
"A biblioteca servia mais como uma coisa de apresentação de escolas, às vezes nós perdemos muito o interesse. $\mathrm{O}$ arquivo em livro nunca brilhou os olhos, pelos menos aqui no interior, em Benjamin, o interesse das pessoas e da administração pública em conservar o espaço. Se tem e se diz que tem uma biblioteca, mas essa biblioteca é quase inútil. Por que se ela só está aí fisicamente e ninguém usa ela, o papel dela não está sendo cumprido. Os indígenas não vêm à biblioteca em busca de informação, sobre o tema indígena, vem estudantes da universidade. Não há nenhum acervo voltado para eles." (Almeida, 2017, I nformação verbal).
\end{abstract}

Sobre o atendimento às minorias linguísticas, e dentre esses, extensivo aos estrangeiros, argumentou que até então isso não havia sido pensado. Para os indígenas, porém, argumentou a existência de material produzido na região por estudantes da Universidade Federal do Amazonas. Sua dissertação de mestrado, inclusive, analisa os rumos do movimento indígena e o processo de organização política dos Ticuna. Além disso, comentou sobre a existência da Biblioteca especializada do Museu Maguta. Sobre a relação de busca da população em geral pela Biblioteca, concluiu dizendo que se houvesse Internet provavelmente a situação seria diferente e que era necessário gerar essa oportunidade.

Nas entrevistas voltadas para o ambiente gestor e administrativo, de positivo todos os entrevistados destacaram a excelente localização da Biblioteca na área central da cidade. 
Quadro 3 - Aspectos positivos e negativos apontados pelos entrevistados.

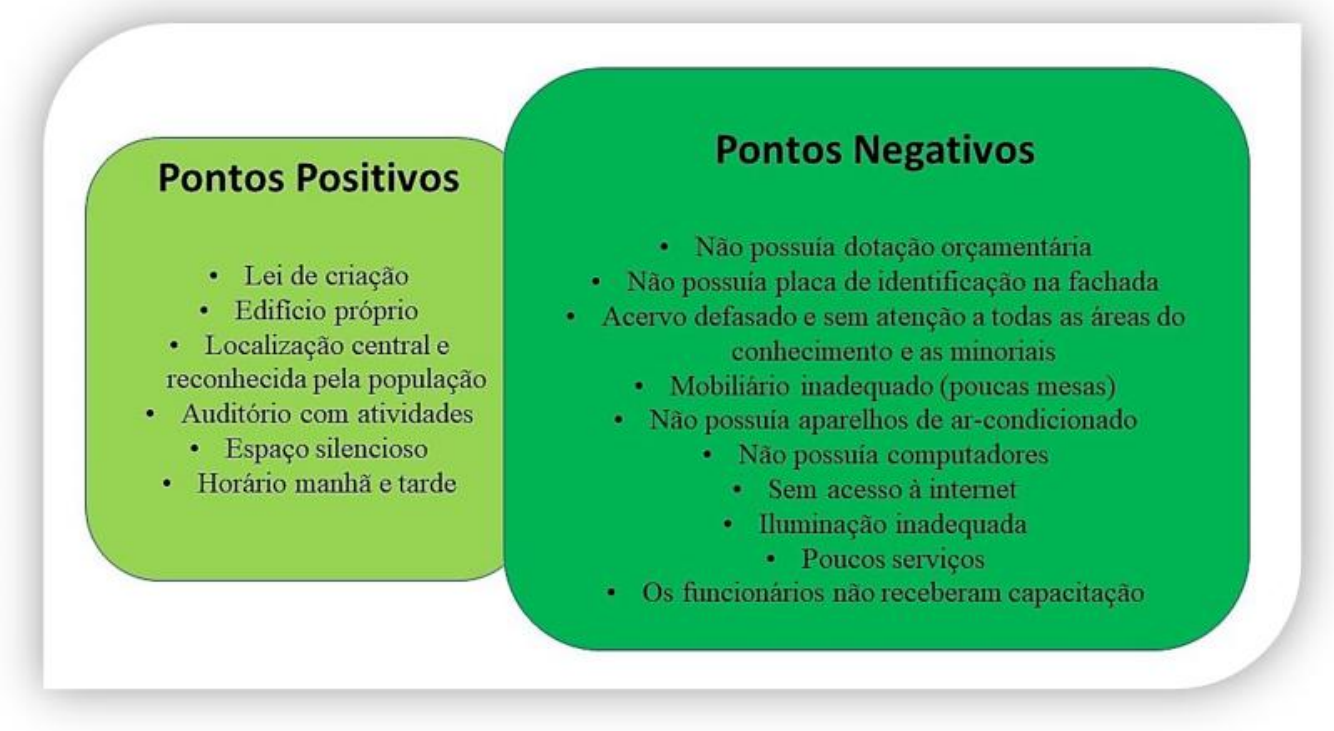

Fonte: A autora (2019)

No quadro 3, estão listados os aspectos positivos e negativos apresentados pelos entrevistados. De acordo com um dos funcionários que atuava por quatro anos na Biblioteca Pública Municipal, entre 2013 a fevereiro de 2017 não houve qualquer interação, contato telefônico ou envio de material oriundo do Sistema Estadual de Bibliotecas Públicas do Amazonas.

O auditório era o local de maior contato e mobilização da Biblioteca Pública; foi relevante observar que, posterior à realização da investigação de campo, uma notícia publicada por Bruno Filho, em 22 de abril de 2017, pelo Blog Bocas e Notícias, apontou a ocorrência de uma atividade comemorativa ao Dia do Índio (19 de abril), realizada pela Secretaria Municipal de Cultura, no auditório da Biblioteca intitulada "As minorias no Brasil: A luta pela garantia de direitos coletivos". Por meio de mesa redonda, Anderson Rocha de Almeida mediava discussão com a presença de lideranças indígenas, inclusive com Josiane Ticuna, liderança feminina na região.

Na avaliação dos entrevistados sobre os serviços, numa escala entre ótimo, bom, regular e péssimo, três apontaram que a biblioteca apresentava serviço regular e um que a biblioteca oferecia péssimo serviço. A falta de apoio advindo da Prefeitura e do SEBP/AM foram apontadas como principais motivos para a condição de poucos avanços.

É válido destacar que no período entre 2004 a 2011 foi implementado pelo governo federal o Programa Livro Aberto voltado para empreender o fortalecimento de bibliotecas públicas nos municípios brasileiros.O programa favoreceu a criação de 1.705 novas bibliotecas e 
682 existentes foram modernizadas. No Amazonas, dos 62 municípios que compõem o estado, 44 receberam Kits de implantação e 10 foram contemplados com Kits de Modernização (SIQUEIRA; MACHADO; LUCK, 2019). Benjamin Constant, contudo não foi beneficiado com Kit de Modernização do Programa Livro Aberto, possivelmente por não ter participado do processo de solicitação via edital. O município perdeu a oportunidade de modernizar seu acervo, bem como adicionar equipamentos, entre os quais computadores, mesas, cadeiras, estantes e outros.

\subsection{Como a população vê a biblioteca pública}

No intuito de conhecer a visão da população do município de Benjamin Constant sobre a biblioteca pública e sua representação social, foi realizada investigação, tomando por base uma mostra populacional composta por 18 pessoas (dois, porém, entrevistados no interior da biblioteca), 10 escolhidos aleatoriamente nas áreas urbanas da cidade, além de seis indígenas da etnia Ticuna. O objetivo central era perceber 0 nível de interação com a biblioteca pública e perceber como este equipamento cultural se expressava simbolicamente no pensamento local.

Nas entrevistas realizadas com os indígenas, três foram entrevistados na área urbana de Benjamin Constant, dos quais o diretor do Museu Maguta e dois estudantes. Outras três entrevistas ocorreram na Aldeia Ticuna Filadélfia, sendo 2 professores e um representante da Organização Geral dos Professores Ticuna Bilíngue (OGPTB), que inclusive apresentou a biblioteca dessa organização.

Dentre os seis indígenas entrevistados, apenas dois apontaram ter conhecido a Biblioteca Pública Municipal: a professora Ticuna I. A. B (entrevista 1), da Escola Ebenezer, que revelou ter ido à Biblioteca “... quando fui estudar na cidade, que fui pesquisar, desde lá nunca mais fui" (Informação verbal).

Também, o estudante I. P. de 16 anos, (entrevista 2), estudante da Escola Estadual Imaculada Conceição, localizada na área urbana de Benjamin Constant, apontou também ter visitado o ambiente para fazer pesquisa, mas disse que depois não sentiu vontade de voltar. Ao ser indagado sobre a utilidade da biblioteca na vida das pessoas respondeu "Eu acho que é para ver um livro e eu acho que é para tirar as dúvidas." (Informação verbal).

Dentre os entrevistados, foram relevantes as informações apontadas por Luís A.U., (entrevista 3), professor Ticuna, que afirmou nunca ter visitado a Biblioteca Pública Municipal, mas que havia conhecido as bibliotecas da Universidade Federal do Amazonas (UFAM) e da Universidade Estadual do Amazonas (UEA).Disse, contudo, que apesar de não ter tido acesso à biblioteca pública, gostava de ler. 
Também foi entrevistado Nino Fernandes, liderança indígena (que foi, por várias gestões, diretor do Museu Maguta), ao ser indagado se havia utilizado alguma vez a biblioteca pública municipal, afirmou não a ter conhecido e tomou como justificativa o fato do Museu Maguta possuir sua própria biblioteca. Nino apontou as dificuldades na manutenção do Museu e o estado de abandono da biblioteca especializada. (Fernandes, 2017, I nformação verbal).

Dos 6 indígenas entrevistados, apenas dois afirmaram ter adentrado o espaço da biblioteca, mas que não retornaram. Não souberam apontar o porquê da falta de interesse.

Quanto às demais pessoas entrevistadas, 10 foram abordadas nas ruas de Benjamin Constant (inclusive dois peruanos); todos sabiam a localização da biblioteca, contudo, apenas quatro apontaram ter feito alguma visita ou atividade no espaço, mas havia muito tempo que não frequentavam o local.

Os que apontaram não conhecer o ambiente interno justificaram que não tinham muito interesse por leitura. Indagados sobre como solucionavam suas necessidades informacionais, apontaram resolver tudo por meio de acesso à Internet, fazendo uso de seus aparelhos celulares. $\mathrm{Na}$ visão dos entrevistados, a biblioteca pública é um ambiente limitado aos aspectos bibliográficos. As palavras mais utilizadas para defini-la foram: pesquisa e livros.

A investigação permitiu perceber que a Biblioteca Pública Municipal de Benjamin Constant é reconhecida na sua forma física pela população. Todos sabem onde está localizada e seu grande atrativo é o auditório, onde são realizados encontros, capacitações, palestras e lançamento de livros.

\section{Considerações finais}

O quantitativo populacional indígena brasileiro, assim como as 305 etnias existentes e as 274 línguas apontadas no censo do IBGE, em 2010, não foram capazes de influenciar estudos ou políticas de inclusão no âmbito das bibliotecas públicas para esse grupo minoritário. A Biblioteconomia brasileira tem promovido poucas discussões que tratem sobre o tema das minorias como um todo, mas, especificamente sobre o contexto indígena do país, essa discussão tem sido retardada.

Os Manifestos e Diretrizes apresentados, sem dúvidas são relevantes por propiciar informações sobre o que fazer no campo de atuação em bibliotecas públicas. Faz-se necessário, entretanto, um trabalho mais intenso para que possam ser reconhecidos além dos ambientes acadêmicos ou institucionais. Quanto às publicações brasileiras apresentadas, seria significativo: 
- Uma atualização de Biblioteca Pública: Princípios e Diretrizes(FUNDAÇÃO BIBLIOTECA NACIONAL, 2010), dedicando maior espaço sobre o tema das minorias linguísticas em vista da composição multiétnica do país, como forma de influenciar estudos ou políticas de inclusão no âmbito das bibliotecas públicas.

- Em prol de práticas inclusivas, talvez a retomada de discussões sobre o Manifesto das Bibliotecas da Amazônia (MANIFESTO DAS BIBLIOTECAS DA AMAZÔNIA, 2005), seja um ponto de partida para repensar estratégias locais.

Do ponto de vista focal, a investigação empírica sobre a Biblioteca Pública de Benjamin Constant, município inserido na tríplice fronteira (Brasil, Colômbia e Peru), possibilitou compor um panorama de uma biblioteca pública amazônica, espaço que com 40 anos de existência não alcançou posição representativa no serviço à população vista como multicultural. Para a investigação, foi absolutamente relevante dispor das falas de indígenas da etnia Ticuna sobre o acesso à biblioteca pública, fator que possibilitou perceber considerações semelhantes às impressões dos não indígenas: para ambos a biblioteca pública tem relação direta com os ambientes de pesquisas bibliográficas, sendo vista como espaço com poucos atrativos.

Como resultado das análises, pode-se afirmar que a Biblioteca Pública Municipal Francisco Soares de Assis não desenvolve trabalho significativo no atendimento à população urbana, tampouco para as minorias linguísticas (surdos, mudos, indígenas, estrangeiros). Sem recursos e sem investimentos, a Biblioteca possuía acervo defasado, não dispunha de nenhum material em Braille, áudio-livros ou livros com idiomas além do Português, voltados para a populações falantes da língua Ticuna, espanhola, ou outras línguas; tampouco possuía computadores com acesso à Internet. Também não desenvolvia ações culturais, exercendo atuação restrita à consulta local e empréstimo domiciliar, esse último com pouca ocorrência.

O fato da Biblioteca Pública não ter recebido auxílio ou qualquer orientação advinda dos responsáveis pelo Sistema Estadual de Bibliotecas Públicas do Amazonas, comprometeu a sua condição inicialmente favorável pois dispunha de melhor infraestrutura que a grande maioria dos municípios do estado, contando com prédio próprio, boa localização, acervo e quadro de funcionários. No tocante ao estreitamento de laços, a gestão da Biblioteca pública poderia ter estabelecido diálogo ou parceria com o Museu Maguta, visando o fortalecimento intercultural entre os espaços.

É preciso avaliar, porém que sem atuação profissional responsável e sem a efetiva atenção de lideranças, a inércia de bibliotecas como a do 
município de Benjamin Constant tem criado visões equivocadas quanto sua importância no ambiente das cidades.

Ao comemorar o Ano Internacional das Línguas Indígenas, tanto a ONU, quanto a IFLA objetivavam despertar consciência ao redor do mundo para a importância da preservação de línguas e saberes dos povos indígenas. Finalizadas as comemorações que fixaram debates sobre a importância da comunicação e da linguagem, além da necessidade de se empreender medidas visando a sobrevivência de línguas que correm riscos de serem extintas, é possível afirmar que muito precisa continuar sendo feito. No contexto brasileiro, para além do respeito às culturas e línguas, várias populações indígenas ainda lutam para assegurar o direito de viver em seus próprios territórios.

Quanto ao que a Biblioteconomia brasileira tem realizado em prol das minorias linguísticas? Quase nada, temos muito trabalho a fazer.

\section{Referências}

ALMEIDA, Anderson Rocha de. Anderson Rocha de Almeida: depoimentos [fev. 2017]. Entrevistadora: S. Magalhães, 2017, 16 min, Arquivo mp3. Benjamin Constant: Entrevista concedida para composição de estudos sobre Biblioteca Pública nos municípios do Amazonas.

ALMEIDA, Fábio Vaz Ribeiro de. Desenvolvimento sustentado entre os Ticuna: as escolhas e os rumos de um projeto. Boletim Museu Emílio Goeldi, Belém, v. 1, n. 1, p. 45-110, jan./abr. 2005. Disponível em: http://scielo.iec.gov.br/pdf/bmpegch/pv1n1/v1n1a03.pdf. Acesso 13 set. 2018. Acesso em: 16 jun. 2018.

AMAZONAS. Lei n. 452, de 19 janeiro de 1979. Dá nome à Biblioteca Pública Municipal. Aprovada na Câmara Municipal de Benjamin Constant. (Obtida por meio da pasta de documentos da biblioteca).

A. U., Luís. Luís, A. U.: entrevista 3. [fev. 2017]. Entrevistadores: S. Magalhães, 2017. 11 min. Arquivo mp3. Benjamin Constant: Entrevista concedida para composição de estudos sobre Biblioteca Pública nos municípios do Amazonas.

BRASIL. [CONSTITUI ÇÃO (1988)]. Constituição da República Federativa do Brasil. Brasília, DF: Senado Federal, [2018]. Disponível em: http://www.planalto.gov.br/ccivil_03/Constituicao/Constituicao.htm. Acesso em: 26 mar. 2018.

BRASIL. Lei n. 6.256, de 22 de outubro de 1975. Cria o Fundo Nacional de Apoio ao Desenvolvimento Urbano e dá outras providências. Diário Oficial da União, Brasília, 22 out. 1975. Disponível em: http://www.planalto.gov.br/ccivil_03/leis/L6256.htm. Acesso em: 18 jun. 2018. 
BRUNO FILHO, Olivaldo C. Dia do Índio: Secretaria Municipal de Cultura realiza programação no Dia do Índio em Benjamin Constant. Blog Portal Bocas e Notícias. 22 abr. 2017. Disponível em: http://bocasenoticias.blogspot.com/2017/04/benjaminconstant-am-secretaria.html. Acesso em 28 set. 2018.

CIVALLERO, Edgardo. Bibliotecas indígenas en América Latina: revisión bibliográfica y estado actual de lacuestión a nivel internacional. Córdoba (Argentina): Wayrachaki, 2008, 81 p. Disponível em:

file:///C:/Users/USER/Downloads/CivalleroEdgardo2007.BibliotecasindigenasRevisionbiblio graficayestadoactualdelacuestionanivelinternacional.pdf. Acesso em: 11 mar. 2019.

FERNANDES, Nino. Nino Fernandes: depoimentos [fev. 2017]. Entrevistadora: S. Magalhães, 2017. 12 min. Arquivo mp3. Benjamin Constant: Entrevista concedida para composição de estudos sobre Biblioteca Pública nos municípios do Amazonas.

FRANCA, Aline da Silva. Do cocar ao catálogo: a representação bibliográfica da autoria indígena no Brasil. 2016. Dissertação (Mestrado em Biblioteconomia) - Centro de Ciências Humanas e Sociais, Programa de Pós-Graduação em Biblioteconomia, Universidade Federal do Estado do Rio de Janeiro (UNIRIO), Rio de Janeiro, 2016. Disponível em: http://www.repositoriobc.unirio.br:8080/xmlui/bitstream/handle/unirio/11150/FRANCA_201 6_disserta\%C3\%A7\%C3\%A30\%20$\% 20$ vers\%C3\%A30\%20correta.pdf?sequence=1\&isAllowed=y. Acesso em: 26 fev. 2019.

FREIRE, José R. Bessa. A descoberta do museu pelos índios. Terra das Águas, Revista semestral do Núcleo de Estudos Amazônicos da Universidade de Brasília, ano 1, n.1, 1999. Disponível em: file:///C:/Users/USER/Downloads/A_Descoberta_dos_Museus_pelos_ndios\%20(1).pdf. Acesso em: 8 jan. 2020.

FUNDAÇÃO BIBLIOTECA NACIONAL. Biblioteca pública: princípios e diretrizes. 2. ed. Rio de Janeiro: Fundação Biblioteca Nacional, 2010.

I. A. B. I. A. B.: Entrevista 1. [fev. 2017]. Entrevistadora: S. Magalhães, 2017. 10 min. Arquivo mp3. Benjamin Constant: Entrevista concedida para composição de estudos sobre Biblioteca Pública nos municípios do Amazonas.

IBGE - INSTITUTO BRASILEIRO DE GEOGRAFIA E ESTATÍSTICA. Benjamin Constant, Amazonas. Disponível em: https://cidades.ibge.gov.br/brasil/am/benjamin-constant/panorama. Acesso em:28dez. 2019. 
IBGE - INSTITUTO BRASILEIRO DE GEOGRAFIA E ESTATÍSTICA. OS indígenas no Censo Demográfico 2010. Disponível em:

https://indigenas.ibge.gov.br/images/indigenas/estudos/indigena_censo2010.pdf. Acesso em: 16 mar. 2017.

IFLA-I nternational Federation Library Association. Celebrates the International Year of Indigenous Languages 2019. Disponível em: https://www.ifla.org/node/91892? fbclid=IwAR16_dCSijGbUbXvqXvBdO3F31S6cfsywtpSA_mHr7MJ1fUFgJ849AN7c0. Acesso em: 21 jan. 2019.

IFLA/UNESCO. Manifesto da IFLA/Unesco sobre Bibliotecas Públicas 1994. Disponível em: https://www.ifla.org/files/assets/public-libraries/publications/PLmanifesto/pl-manifesto-pt.pdf. Acesso em: 9 jul. 2018.

I. P. I. P: Entrevista 2. [fev. 2017]. Entrevistadora: S. Magalhães, 2017. 5 min. Arquivo mp3. Benjamin Constant: Entrevista concedida para composição de estudos sobre Biblioteca Pública nos municípios do Amazonas.

KOONTZ, Christie; GUBBIN, Barbara. Diretrizes da IFLA sobre os serviços da Biblioteca Pública. Edição inteiramente revista. Lisboa: Direção-Geral do Livro, dos Arquivos e das Bibliotecas, 2013, 120 p. Disponível em: https://www.ifla.org/files/assets/hq/publications/series/147-pt.pdf. Acesso em: 30 jul. 2018.

MANIFESTO DAS BIBLIOTECAS DA AMAZÔNIA. Belém: Editora Cejup, 2005, 31 p. Disponível em:

https://www2.senado.leg.br/bdsf/bitstream/handle/id/532779/Manifesto_das_Bibliotecas_da_ Amazonia.pdf?sequence=1. Acesso em: 6 jan. 2019.

ONU - ORGANIZAÇÃO DAS NAÇÕES UNIDAS. DECLARAÇÃO UNIVERSAL DOS DIREITOS HUMANOS. Adotada e proclamada pela Assembleia Geral das Nações Unidas (resolução 217 A III) em 10 de dezembro 1948. UNICEF, Brasil. Disponível em: https://www.unicef.org/brazil/declaracao-universaldos-direitos-humanos Acesso em: 8 jan. 2019.

ONU - ORGANIZAÇÃO DAS NAÇÕES UNIDAS. ONU celebra Ano Internacional das Línguas Indígenas pela primeira vez. ONU News. Disponível em: https://news.un.org/pt/story/2019/01/1656932. Acesso em: 4 mar. 2019.

PEN CLUBE PORTUGUÊS. Declaração Universal dos Direitos Linguísticos (1996). Disponível em: http://www.penclubeportugues.org/comites/declaracaouniversal-dos-direitos-linguisticos/. Acesso em: 8 jan. 2019.

SCHOR, Tatiana; OLIVEIRA, José Aldemir de. Reflexões metodológicas sobre o estudo da rede urbana no Amazonas e perspectivas para a análise 
das cidades na Amazônia brasileira. ACTA Geográfica, Roraima, Ed. Esp. Cidades na Amazônia Brasileira, p. 15-30, 2011. Disponível em: http://revista.ufrr.br/index.php/actageo/article/view/539/628. Acesso em: 13 mar. 2017.

SIQUEIRA, Bianca Lopes; MACHADO, Elisa Campos, LUCK, Ester Hermes. O papel do Sistema Nacional de Bibliotecas Públicas na construção de políticas públicas. Revista Brasileira de Biblioteconomia e Documentação, v. 15, n. 2, maio/ago., 2019. Disponível em:

https://rbbd.febab.org.br/rbbd/article/view/1221. Acesso em: 15 dez. 2019.

SUAIDEN, Emir-José. La biblioteca publica y lascompetenciasdel siglo XXI: The public library and the skills of the XXI century. El profesional de la información, España, v. 27, n. 5, p. 1136-1144, sept./oct., 2018. Disponível em:

http://www.elprofesionaldelainformacion.com/contenidos/2018/sep/17.pdf. Acesso em: 6 jan. 2019. 